See discussions, stats, and author profiles for this publication at: https://www.researchgate.net/publication/275349038

Metáforas legitimadoras del inmigrante irregular en la prensa norteamericana en lengua española / Legitimizing metaphors of irregular immigration in the Spanish language press in $\mathrm{t} . .$.

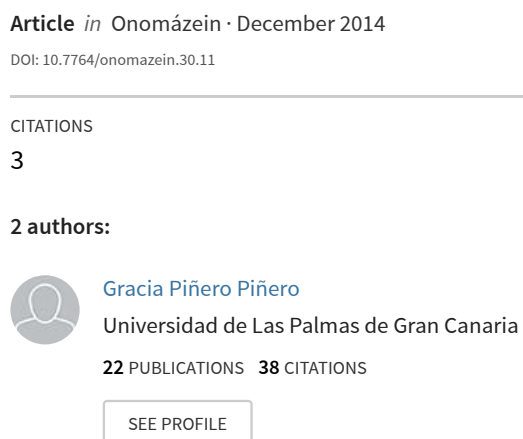

READS

58

University of California, San Diego

24 PUBLICATIONS 316 CITATIONS

SEE PROFILE 


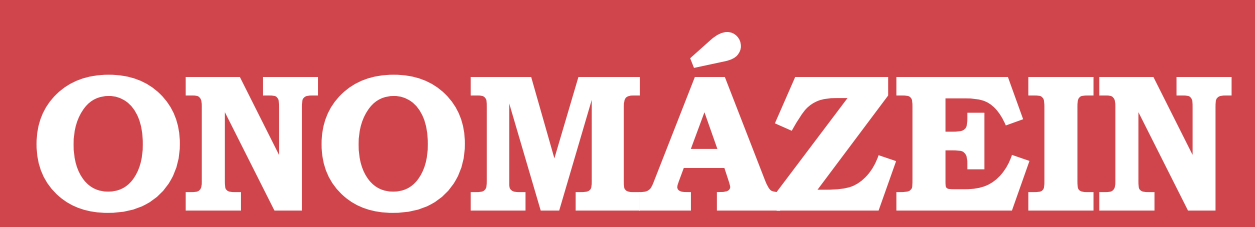

Revista semestral de lingüística, filología y traducción
PONTIFICIA UNIVERSIDAD CATÓLICA DE CHILE CATOLICA DE CHILE
FACULTAD DE LETRAS

\title{
Metáforas legitimadoras del inmigrante irregular en la prensa norteamericana en lengua española
}

Legitimizing metaphors of irregular immigration in the Spanish language press in the United States

\section{Gracia Piñero Piñero}

Universidad de Las Palmas de Gran Canaria

España

\author{
John Moore \\ University of California San Diego \\ Estados Unidos
}

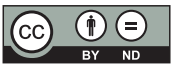

Gracia Piñero: Departamento de Filología Española, Universidad de Las Palmas de Gran Canaria, España. | Correo electrónico: gpinero@dfe.ulpgc.es

John Moore: Department of Linguistics, University of California San Diego, Estados Unidos.

| Correo electrónico: moorej@ucsd.edu 


\section{Resumen}

Frente a los estudios del discurso político relacionado con la inmigración, que se han ocupado preferentemente del retrato del inmigrante efectuado por sus detractores, este trabajo descubre la imagen del inmigrante según la dibujan las voces de ideología contraria, que lo defienden y respaldan haciendo uso de un discurso de resistencia, que cuestiona los acontecimientos tal y como los exponen sus adversarios y que presenta su propia interpretación de esos mismos acontecimientos.

Para ello, a partir de un corpus constituido por artículos de opinión aparecidos en publicaciones en lengua española específicamente dirigidas a la población hispana residente en el condado estadounidense de San Diego, hemos analizado las metáforas conceptuales y lingüísticas a las que recurren estas voces para reproducir la vida del inmigrante irregular y ciertos aspectos relevantes del universo cognitivo en el que se desenvuelve, tales como el país anfitrión; el permiso de residencia, documento capaz de liberarlo del estigma de ilegal, o la aportación que supone el inmigrante, en opinión de estas voces, para el país receptor.

A través de este análisis se comprueba que la metáfora se emplea con la intención de legitimar al inmigrante indocumentado, de convertirlo en miembro competente del orden social establecido; para ello, el usuario aplica una serie de procesos cognitivos, entre los que destaca la elección de dominios fuente, que subrayan insistentemente aquellos aspectos que se pliegan a su ideario y que resultan en un cuerpo conceptual coherente, revelador de la ideología del grupo social que las genera.

Palabras clave: metáfora; inmigración; inmigrante; legitimación; ideología; prensa.

\section{Abstract}

In contrast to studies of the political discourse related to immigration which have focused principally on the portrayal of immigrants through the eyes of their detractors, this article reveals the image of immigrants effected by the voices of the opposing ideology who defend and support them. These voices make use of a discourse of resistance which questions events as they are depicted by their adversaries and which presents its own interpretation of these same events.

Drawing on a corpus made up of opinion articles from Spanish language publications targeted at the Hispano population in the U.S. county of San Diego, we have analyzed the conceptual and linguistic metaphors used by these voices to describe the life of irregular immigrants and certain relevant aspects of the cognitive universe in which their life unfolds, such as the host country; the residence permit, the document capable of freeing them from the stigma of illegality, or, in the opinion of these voices, the contribution the immigrant makes to the host country.

Through this analysis, we find that metaphors are employed with the intention of legitimizing undocumented immigrants and converting them into competent members of the established social order. In order to do this, the user applies a series of cognitive processes among which the choice of source domain stands out as the element which constantly highlights this idea, making up a coherent conceptual picture that reveals the ideology of the social group which generates it.

Keywords: metaphor; immigration; immigrant; legitimization; ideology; press. 


\section{Introducción}

Se ha afirmado que el discurso político suele construirse a partir de estrategias de conceptualización binaria (Chilton, 2004), de entre las que alcanza especial relevancia el patrón nosotros / los otros, encaminado a representar al propio grupo de forma positiva y al ajeno, de forma negativa. En el discurso político en torno a la inmigración, esta estrategia suele orientarse hacia la deslegitimización del colectivo de inmigrantes, de los otros (Van Dijk, 1999, 2005, 2006; Casero, 2007; Semino, 2008), que, a través de procesos de depreciación más o menos intensos, queda despojado de su condición de humano y degradado a niveles inferiores de la Gran Cadena del Ser (Lovejoy, 1936; Lakoff y Turner, 1989), tales como el de los animales o, ya en su grado extremo, el de los objetos, sustancias o seres inanimados (Santa Ana, 1999, 2002, 2003; Flores, 2003; Cisneros, 2008; Semino, 2008; Musolff, 2011).

Este discurso dominante de carácter xenófobo, que considera al inmigrante como un elemento externo, excluido de la sociedad, ha generado una respuesta de parte de voces de ideología contraria, que se solidarizan emocionalmente con el inmigrante y que, por ello, construyen un discurso disidente, de resistencia al anterior, que pone en duda los acontecimientos tal y como quedan expuestos por sus interlocutores presentando su propia interpretación de esos mismos acontecimientos (Pinero-Pinero y otros, 2014).

La práctica discursiva se constituye de este modo en una forma de acción social, en un discurso ideológico (Van Dijk, 1996: 25), que sirve para sustentar o cuestionar determinadas posiciones sociales; a través de él el autor interpreta y construye los hechos, sus protagonistas y las relaciones sociales que se establecen entre ellos (Martín y otros, 1998). Como afirma Foucault (2002: 123), "el discurso transporta y produce poder, lo refuerza pero también lo mina, lo expone, lo torna frágil y permite detenerlo”.
Naturalmente, somos conscientes de que el fenómeno migratorio es bastante más complejo y, por ello, la lógica de polarización que suele aplicarse a este debate no es ni mucho menos real y efectiva. No obstante, el debate público en torno a la inmigración no reconoce matices y suele partir de esta simplificación recurriendo a una retórica melodramática, que se distingue principalmente por el modo "in which it presents its characters" (Osborn y Bakke, 1998). Efectivamente, los personajes melodramáticos poseen ciertos rasgos distintivos, que contribuyen a esta polarización de la realidad y entre los cuales Osborn y Bakke (1998) destacan los siguientes: "represent moral absolutes, [...] are incredibly simple representations of humanity [...], are rigid and unchanging [...], represent class or group portraits [...], and justify arguments". Son precisamente estas características las que convierten al melodrama en un patrón narrativo especialmente idóneo en el terreno de la política: "melodrama is the realm of social action, public action, actions within the world" (Heilman, 1968).

Los estudiosos de los textos relacionados con la inmigración se han ocupado preferentemente del retrato del inmigrante elaborado por sus detractores, por sus adversarios, por quienes lo conceptúan como una realidad negativa $y$, por ello, como enemigo al que hay que combatir (Santa Ana, 1999, 2002, 2003; Flores, 2003; Cisneros, 2008; Semino, 2008; Musolff, 2011). En consonancia con esta conceptualización, la imaginería aplicada al fenómeno de la inmigración suele construirse acudiendo a dominios conceptuales diversos que comparten una evaluación negativa, en tanto que subrayan emociones y juicios descalificadores. Así, la inmigración irregular se proyecta sobre el escenario de los desastres naturales, que cristaliza en el discurso xenófobo a través de términos como flood, wave, tide, inundate, dangerous waters o eruption, no solo para enfatizar las connotaciones dañinas asociadas a estas catástrofes, sino también para introducir 
efectos deshumanizadores, en tanto que oculta la individualidad de los inmigrantes para reducirlos a una masa indiferenciada. De igual modo, se establece una correspondencia entre la inmigración y el marco conceptual de la guerra, para dramatizar la gravedad de un enfrentamiento entre grupos de individuos que defienden intereses encontrados. Mediante esta categorización, las diversas nociones que configuran un escenario bélico se utilizan para razonar a propósito del dominio meta mediante un juego de correspondencias que identifican al inmigrante con el enemigo que amenaza el bienestar de los países civilizados y, por ello, como un fenómeno que debe ser erradicado. En la misma línea, se acude al escenario de la enfermedad y de la herida para retratar negativamente el fenómeno migratorio, identificado entonces con la afección o el desgarramiento que aqueja al país anfitrión.

Nuestro objetivo, sin embargo, es descubrir la imagen del inmigrante tal y como la dibujan las voces de ideología contraria, que lo respaldan y lo defienden. Teniendo en cuenta el citado marco de conceptualización binaria nosotros / los otros, observaremos, por tanto, el modo en que esos otros, los valedores sociales y políticos del inmigrante irregular, conceptualizan esta esfera de la experiencia aplicando estrategias legitimadoras que pretenden poner de manifiesto que los inmigrantes "se consideran miembros competentes y moralmente rectos del orden social" (Martín y Van Dijk, 1998: 183) y que resultan en una representación positiva, en la que incluso ellos mismos - como se verá en algunas de las muestras extractadas - se reconocen, porque entienden que interpretan la realidad tal y como ellos la perciben, la sienten.

A través de un corpus de textos que seguidamente delinearemos, descubriremos este retrato positivo mediante el análisis de las metáforas conceptuales a las que recurren estas voces para reproducir la vida del inmigrante irregular y ciertos aspectos relevantes del universo cognitivo en el que este se desenvuelve. Nótese que nos re- ferimos específicamente a aquel que dispone de la condición de irregular, derivada de la circunstancia de carecer de permiso de residencia en el país y de hallarse, por tanto, en situación de ilegalidad. Pretendemos, consecuentemente, una investigación cualitativa, que, más allá del grado de frecuencia con el que estas metáforas afloran en los textos, descubra los perfiles, los tonos con que se colorea la vida de estos inmigrantes y el mundo que habitan.

Para ello, haremos uso de la teoría de la metáfora conceptual (Lakoff y Johnson, 1980, 1999; Johnson, 1987, 1993; Lakoff, 1987, 2008; Lakoff y Turner, 1989; Turner, 1991; Sweetser, 1990; Kövecses, 2002, 2005), entendida como una herramienta que permite categorizar dominios complejos y abstractos, como es en este caso el de la inmigración y el inmigrante, a través de su asociación con otros más sencillos, más concretos y, por ello, más asequibles. Comprobaremos que, a través de las metáforas, no solo exportamos realidades del dominio origen, sino también, y lo que es más importante, nuestra valoración, nuestras actitudes, creencias y emociones a propósito de esas mismas realidades. De este modo, la elección de metáforas contribuye de manera esencial al anclaje ideológico de estos textos (Haynes, 1989), mediante operaciones cognitivas que van desde la elección de dominios y la distribución de roles hasta el establecimiento de un entramado de emociones. Como afirma Lakoff (2006: 119), “[...] they have an implicit or explicit narrative structure, i.e., they all tell stories with heroes, villains, victims, common themes, etc.".

\section{Descripción del corpus}

Con el fin de localizar la voz de los otros, de los benefactores del inmigrante, hemos dirigido nuestra mirada al condado estadounidense de San Diego, en el que, como es sabido, reside una nutrida comunidad de inmigrantes mexicanos, buena parte de los cuales se halla en situación de ilegalidad. Esta circunstancia ha propiciado la aparición de diversos periódicos en lengua es- 
pañola específicamente dirigidos a la población hispana residente en esta área ${ }^{1}$

Estos periódicos contienen abundantes artículos de opinión que surgen con la intención de participar en el debate político introduciendo la réplica al discurso xenófobo al que aludíamos al comienzo. Sus autores ejercen su compromiso social mediante textos que, partiendo de estrategias de legitimación del inmigrante, denuncian la situación de precariedad en que se halla, al tiempo que proponen medidas encaminadas a mejorar su situación.

Los medios de comunicación a los que hacemos referencia son tres publicaciones californianas de distribución semanal denominadas Frontera San Diego, El Latino y La Prensa de San Diego, destinadas a la creciente comunidad hispana residente en el área y especialmente a la comunidad mexicana. De ellas hemos extraído un total de 119 artículos de opinión aparecidos entre los meses de septiembre y diciembre de $2011^{2}$, que, por definición, desarrollan una argumentación que pretende obtener la adhesión del receptor. Al servicio de esta función persuasiva se disponen mecanismos diversos, entre los cuales desempeña un papel esencial la metáfora conceptual (Semino, 2008: 85-86).

\section{Análisis: metáforas conceptuales del inmigrante irregular y de aspectos relevantes de su universo cognitivo}

Con estos presupuestos, hemos extractado y examinado las metáforas conceptuales y lingüísticas que reproducen la vida del inmigrante irregular y ciertos aspectos relevantes de su universo cognitivo. Con ellas, sus autores, en tanto que miembros de una cultura y de un grupo en particular, muestran el modo en el que perciben y piensan este aspecto de la realidad social, a través de esta interacción que es el discurso (Condor y Antaki, 2000: 454). Se trata de un conjunto de analogías relativamente heterogéneo, que hemos agrupado, del modo que hemos creído más coherente, en tres bloques diferentes: el primero de ellos aglutina las metáforas que trazan la existencia del inmigrante irregular; el segundo recoge las analogías referidas a realidades trascendentales de la vida del indocumentado, tales como el país anfitrión, que lo ha acogido y en el que ha construido una nueva vida, y el permiso de residencia, ese documento que le otorga la capacidad de desprenderse de su condición de irregular3; un último bloque reúne las asociaciones metafóricas que reproducen el punto de vista de los defensores del inmigrante irregular sobre lo que este representa para el país anfitrión, en el que reside y a cuyo sostenimiento, manifiestan, también contribuye. En los próximos epígrafes expondremos y valoraremos estas proyecciones metafóricas.

\subsection{Conceptualización metafórica de la existencia del inmigrante irregular}

Como ya hemos advertido, en el tratamiento que hacen los medios de la cuestión migra-

1 Para contextualizar el corpus, conviene tener presente que la ciudad de San Diego se encuentra separada de la ciudad mexicana de Tijuana por el cruce fronterizo de mayor flujo del mundo. Aquí tiene lugar el punto de encuentro de un país industrializado y desarrollado con un país opuesto en su configuración socioeconómica, cultural y educativa. Por otra parte, además, parece oportuno recordar la promesa electoral efectuada por Obama durante la campaña electoral que lo Ilevó a ocupar por primera vez la presidencia de EEUU de desarrollar una reforma migratoria federal, de carácter global, que resolviera y regulara la situación de los inmigrantes residentes en el país en situación de ilegalidad. El hecho de que, por el momento, el gobierno federal de EEUU no haya acometido tal reforma ha favorecido la aparición de medidas y leyes estatales heterogéneas, a las que frecuentemente aluden los autores de los textos objeto de estudio, con las que cada uno de los estados ha pretendido reglamentar la situación de este colectivo.

2 Hemos de recordar que es en estas fechas cuando el debate migratorio se convierte en protagonista habitual de la actualidad informativa de EEUU, pues, como hemos advertido, la promesa de acometer una reforma migratoria federal efectuada por Obama no se ha llevado a cabo y su primer mandato presidencial se encuentra en el tramo final.

3 Las leyes de control migratorio con las que el país receptor combate al inmigrante irregular constituyen también parte esencial del universo cognitivo en el que este se desenvuelve; por razones de espacio, sin embargo, son objeto de un estudio aparte, que, en estos momentos, está en fase de desarrollo. 
toria reconocemos una contraposición entre el discurso de la seguridad, que apela a la instauración de obstáculos o límites que impidan la entrada de extranjeros, quienes, de este modo, quedan conceptualizados como una amenaza, como un peligro, y el discurso de la solidaridad, que contempla al inmigrante como un individuo desvalido, que debe ser objeto de ayuda y comprensión (Casero, 2004, 2007).

Las analogías localizadas en nuestro corpus responden precisamente a este discurso de la solidaridad $y$, consecuentemente, insisten en conceptualizar al inmigrante como un sujeto intimidado, víctima de una persecución. Especialmente ilustrativos de la paleta sombría seleccionada por los defensores de este colectivo para colorear la existencia del inmigrante indocumentado son los dominios fuente a los que acuden para representarla metafóricamente: PESADILLA, ACTIVIDAD ARRIESGADA O TABLERO DE AJEDREZ. TOdos ellos subrayan, como veremos, la angustia, el padecimiento, el peligro y la dificultad como rasgos definitorios de su vida, con la intención de persuadir a la audiencia de la necesidad de solidarizarse emocionalmente con él, porque, como afirma Chilton (1996: 320), "the way people conceptualize and communicate is an intrinsic part of policy and action".

El primero de estos dominios, PEsadilla, ese sueño angustioso que se repite insistentemente, se proyecta metafóricamente sobre la existencia del inmigrante que carece de permiso de residencia para representarla como una realidad dolorosa, difícil. Con esta metáfora no estructural (Ruiz de Mendoza y Pérez, 2011), el usuario subraya la angustia como cualidad esencial de la existencia del inmigrante para evidenciar la necesidad de poner en marcha medidas que alivien su padecimiento $y$, consecuentemente, de combatir ese cuerpo legislativo, del que forma parte la Operación Endgamé, a la que alude el fragmento, destinado a erradicar al inmigrante irregular:

El proyecto, que contemplaba la expulsión del país de todos los indocumentados entre 2003 y 2012, no cumplirá la meta para la fecha fijada, pero sí sentó las bases para confeccionar la pesadilla que viven los inmigrantes que carecen de papeles (LPSD, 11-11-2011) $)^{5}$

El segundo de los marcos fuente aludidos, que, con la idea de evitar una excesiva atomización, hemos designado ActividAD ARRIESGADA, supone un salto cualitativo a la hora de oscurecer los tonos que tiñen la vida del inmigrante, identificada ahora con labores que, además de tener lugar durante la vigilia, cuando se está plenamente despierto y consciente, se definen en esencia por las nociones de riesgo, inseguridad y peligro.

De nuevo, una metáfora no estructural, que, "unlike structural metaphors, work by highlighting one attribute or a tight-knit cluster of related attributes that are perceived to be similar across domains" (Ruiz de Mendoza y Pérez, 2011). Con ella, a la condición de angustia consustancial a la pesadilla, se une ahora el factor de inseguridad y peligro incorporado por esta actividad arriesgada, que, en la primera de sus instanciaciones, se concreta en el juego de la ruleta rusa:

Sin licencia de manejar, sin papeles y con la HB 56 conducir al trabajo es una ruleta rusa. "Uno se la está jugando y sale a trabajar sólo porque es su responsabilidad hacerlo. Por mi señora y mi nena porque los Pampers no se compran solos", indicó el esposo de Lizbeth, que trabaja en un aserradero (EL, 21-10-2011).

La proyección conceptual que se establece entre la vida del inmigrante, condensada aquí en

4 Con el nombre de Operación Endgame fue bautizado un plan desarrollado durante el periodo $2003-2012$ por la Office of Detention and Removal Operations of the U.S. Department of Homeland Security Bureau of Immigration and Customs Enforcement, para detener y deportar a los extranjeros sin permiso de residencia y a los sospechosos de terrorismo residentes en EEUU.

5 Las iniciales que figuran tras cada uno de los fragmentos indican el medio del que han sido extraídos: EL (El Latino), FSD (Frontera San Diego) y LPSD (La Prensa de San Diego). 
la acción de conducir al trabajo, y el juego letal de la ruleta rusa focaliza el peligro y el drama como marcas esenciales de la existencia de quien, sin permiso de residencia y con leyes como la HB 56 del estado de Alabama 6 , ha de luchar contra obs táculos que amenazan con destruir sus actuales condiciones de vida.

En otras ocasiones, la actividad arriesgada se particulariza en un deporte de alto riesgo. Una vez más, la metáfora conceptual insiste en la noción de peligro como definitoria de su existencia: el indocumentado es un deportista de alto riesgo, practica una actividad que comporta inseguridad o amenaza, dadas las condiciones difíciles o extremas en que se desenvuelve. En este caso, esa amenaza se proyecta sobre la vida del inmigrante, enfrentado a diario con escollos tales como la detención o la deportación, que pueden derribar su infraestructura familiar y económica:

\section{- Pero ser político es emocionante.}

- Cretino, si quieres emociones, te pagamos cualquier otro deporte de alto riesgo. ¿Quieres ser paracaidista? ¿Piloto de Nascar? ¿Indignado en Wall Street? ¿Compañero de cacería del vicepresidente Cheney? ¿Trabajador indocumentado? (EL, 11-11-2011).

Conviene subrayar el componente de azar que reconocemos en ambas instanciaciones de la metáfora - juego de la ruleta rusa y actividad arriesgada-, del que se desprende que el inmigrante queda expuesto a situaciones cuya resolución no depende esencialmente de su habilidad o destreza, sino de la suerte, siempre incontrolable, fortuita. El inmigrante vive así una vida cuyas riendas están en manos de otro, desconocido, ajeno y muchas veces antagonista.

Finalmente, se acude al dominio fuente JUEGO DEL AJEDREZ para establecer proyecciones a propósito del inmigrante y de su existencia (Pinero-Pinero y otros, 2014). Este juego, metáfora de la guerra por excelencia, representa una batalla entre dos partes, que desarrollan tácticas y estrategias encaminadas a la destrucción del adversario, quien queda definitivamente derrotado mediante el jaque mate o lance final. En el contexto, por tanto, de una metáfora de mayor amplitud como es LA INMIGRACIÓN IRREGULAR ES UNA PARTIDA DE AJEDREZ, el dominio fuente proporciona una serie de subcategorías que contribuyen a dibujar un escenario bélico y que encuentran su correspondencia en el marco meta.

Así, los rivales se vinculan con los defensores y detractores del inmigrante indocumentado; las jugadas que se suceden en la partida se proyectan sobre las estrategias, leyes y medidas políticas desarrolladas por el país anfitrión para combatir la inmigración indocumentada7; y, por último, el tablero del ajedrez sobre el que tiene lugar la partida, con sus múltiples escaques de color blanco y negro, se identifica figuradamente con la vida del inmigrante indocumentado, quien, al igual que el jugador de ajedrez, debe encarar los conflictos que el tablero de su existencia le plantea en cada escaque, en cada momento. Aunque todas estas proyecciones permanecen conceptualmente accesibles a través de procesos inferenciales (Ruiz de Mendoza y Pérez, 2011), en los textos objeto de estudio solo se activan algunas de ellas.

6 La ley HB 56 del estado de Alabama, aprobada en junio de 2011 con el fin de luchar contra la inmigración ilegal, resulta especialmente controvertida en algunos de sus aspectos, como es que el Estado pueda exigir a la policía la detención de personas sospechosas de estar en el país de manera ilegal; la obligación de las escuelas públicas de determinar, mediante la revisión de certificados de nacimiento o declaraciones juradas, la condición de residentes legales de los estudiantes en el momento de la inscripción; o poner en duda la legalidad de los contratos de trabajo de personas que carecen de permiso de residencia.

7 Como hemos señalado, la conceptualización metafórica de las leyes de control migratorio efectuada por voces que se solidarizan emocionalmente con el inmigrante irregular es objeto de estudio de un trabajo en curso. En él ponemos de manifiesto que tales metáforas reflejan la percepción de quienes se sienten lesionados y oprimidos por el grupo social dominante. Contienen, por tanto, una narrativa de opresión, contrapunto de la narrativa de hegemonía identificada en las metáforas empleadas por el discurso político hostil hacia este colectivo (Santa Ana, 2002, 2003). 
De este modo, las dos últimas proyecciones señaladas se conforman en nuestros textos a través de dos submetáforas subordinadas a la metáfora madre LA INMIGRACIÓN IRREGULAR ES UNA PARTIDA DE AJEDREZ. La primera de ellas (LA OPERACIÓN ENDGAME ${ }^{8}$ ES UNA JUGADA) asocia figuradamente un movimiento de la partida con una de las acciones diseñadas por el gobierno estadounidense, la denominada Operación Endgame, para detener y deportar a los extranjeros sin permiso de residencia y a los sospechosos de terrorismo. Además, el término con el que se bautiza esta operación nos remite igualmente al marco del ajedrez, donde endgame alude a esa fase del juego en la que quedan pocas piezas sobre el tablero:

Cuando Anthony Tangemann, director de la Oficina de Detención y Remoción (DRO), del Servicio de Inmigración y Control de Aduanas (ICE), ordenó la realización de la Operación Endgame (Final del Juego) en el verano de 2003, movió las piezas de ajedrez que tienen hoy a los 11 millones de indocumentados contra el filo de la deportación (LPSD, 11-11-2011).

Por otra parte, además, en el título del artículo en el que se inserta la muestra anterior (Jaque mate a los indocumentados) se concibe la mencionada Operación Endgame como el jaque mate o lance final contra los indocumentados, de manera que este movimiento de ataque al rey que supone el final del juego y la derrota definitiva del contrincante se proyecta metafóricamente en el dominio meta sobre la eliminación de la inmigración irregular.

En nuestro caso, nos interesa particularmente la segunda de las submetáforas citadas, que proyecta el tablero del ajedrez sobre la vida del inmigrante irregular para dar lugar a la imagen LA VIDA DEL INMIGRANTE IRREGULAR ES UN TABLERO DE AJEDREZ, instanciada en la expresión idiomática española hacer la vida de cuadritos:

O como este joven, pueden ser héroes cuya rápida gestión impidió que el secuestro de la niñita terminara en tragedia y lo hizo sin importarle su situación migratoria y si esto finalmente lo afectaría en un estado como Nuevo México donde las políticas estatales sumadas a las federales le hacen a diario la vida de cuadritos a las personas sin documentos (LPSD, 09-09-2011).

El modismo hacer la vida de cuadritos, que significa literalmente to make little squares of one's life, parece ser una referencia al tablero de ajedrez, que plantea al jugador dificultades y obstáculos en cada uno de sus cuadros. Ahora son las políticas estatales y federales relacionadas con el control migratorio las que, en sentido figurado, transforman la vida del inmigrante en un tablero, obligándolo, a cada paso, a afrontar peligros o situaciones comprometidas.

En definitiva, los tres marcos origen seleccionados para reproducir la existencia del indocumentado, PESADILLA, ACTIVIDAD ARRIESGADA y TABLERO DE AJEDREZ, disponen de gran impacto retórico, de una potente fuerza emocional, pues intensifican con gran plasticidad los tonos oscuros, enfatizan el padecimiento y la inseguridad como la quintaesencia de la vida del inmigrante. Un procedimiento eficaz cuando se pretende lograr la adhesión de la audiencia con este colectivo, despertando en ella sentimientos de solidaridad con quien sufre estas penalidades. Se trata, por consiguiente, de un discurso comprometido (Bañón, 2008a: 25), que se convierte en práctica social, pues los autores, al tiempo que se resisten, mediante la práctica discursiva, a la ideología xenófoba predominante en el discurso de la prensa en torno a la inmigración, manifiestan su respaldo al inmigrante, a quien se dirigen preferentemente sus textos.

\subsection{Conceptualización metafórica de aspectos relevantes del universo cognitivo del inmigrante irregular}

Recogemos aquí las analogías referidas a algunas de las realidades que entrañan un signi-

8 En la nota número 4 hemos recogido el contenido de la llamada Operación Endgame. 
ficado determinante en la vida del indocumentado: tal es el caso del permiso de residencia, que tiene la capacidad de transformar radicalmente sus circunstancias, liberándolo del estigma de la ilegalidad; tal es el caso, también, del país anfitrión, en el que ha puesto los cimientos de una nueva existencia y en el que le ha sido posible superar de un modo más o menos satisfactorio las dificultades que lo llevaron a abandonar su tierra natal. Ambos espacios meta experimentan un tratamiento metafórico que, según veremos, descubre la ideología de sus usuarios, quienes, al tiempo que denuncian la discriminación que a su juicio sufre este colectivo, hacen uso de una representación positiva del país receptor con el fin de refutarla, de exponer un contraste entre la situación pasada, en la que en su opinión EEUU amparaba al inmigrante, y la situación presente, en la que esta imaginería positiva no se pliega al modo en que los autores del corpus perciben el país anfitrión.

\subsubsection{El permiso de residencia}

La primera de las realidades esenciales al universo cognitivo del inmigrante irregular a las que aludíamos la constituye el permiso de residencia, ese documento que salda definitivamente la situación de ilegalidad en la que se halla. Casero (2007) subraya, al respecto, la trascendencia del eje legal-ilegal en la configuración de la identidad mediática de los inmigrantes y que da lugar a la construcción de una imagen asociada, mayoritariamente, a la esfera de la delincuencia y la inseguridad. Efectivamente, la carencia de este salvoconducto hace recaer sobre el inmigrante un proceso de degradación que lo deshumaniza y lo cosifica, y que se concreta en la asignación, por parte de sus detractores, de la etiqueta de ilegal, mediante la cual el indocumentado, como cualquier otra mercancía, queda clasificado por medio de una marca, de una señal. Este documento, con el que se desvanece el estigma de ilegal y que, por ello, está llamado a desempeñar un cometido crucial en la vida de estas personas, se conceptualiza en nuestro corpus por medio de un dominio fuente, PAPEL - instanciado con variaciones morfológicas-, con el que, en nuestra opinión, los defensores de este grupo minusvaloran la trascendencia que le confieren sus detractores, quienes entienden que la carencia de este documento "viola un principio básico de la vida social civilizada" (Van Dijk, 1996: 25) y quienes construyen la identidad del inmigrante a partir de un objeto físico determinado como es el papel o los papeles (Casero, 2007):

La amenaza crece, nos dirán. Por la frontera sur se nos pueden colar terroristas o narcotraficantes contratados por terroristas. Y como el asunto es matemáticamente posible, los que pagan las consecuencias son los inmigrantes, que no son criminales ni terroristas, y que llevan años trabajando en Estados Unidos esperando un papelito que los haga legales (FSD, 20-10-2011).

Persona muy importante o VIP. Eso es lo menos que muchos sectores piensan sobre los indocumentados porque la falta de un papel los deshumaniza y los vuelve invisibles aunque estén ahí a diario llevando a cabo importantes labores (LPSD, 09-09-2011).

Se trata, en nuestra opinión, de una metáfora que condensa el menosprecio del indocumentado ante el rechazo o la exclusión que experimenta por la circunstancia de no disponer de este papel, que lo degrada a una especie inferior. En efecto, la presentación del inmigrante como sin papeles lo despoja de sus derechos y lo convierte en persona invisible que no goza de ninguna protección, ni tan siquiera de la relacionada con los derechos humanos (Casero, 2007). Por ello, a través de la metáfora objeto de análisis, se introduce una réplica al discurso de los otros, para quienes la posesión de este documento es de tal trascendencia que tiene la capacidad de metamorfosear al inmigrante sin permiso de residencia en una persona radicalmente diferente, regular, legal, aceptable; los autores de nuestro corpus entienden, desde su particular perspectiva, que la posesión de este salvocon- 
ducto, aunque indudablemente le abre puertas trascendentales, no hace al indocumentado una persona distinta a la que es cuando carece de él.

\subsubsection{El país de acogida}

Pieza esencial también de la cognición social (Condor y Antaki, 2000) del inmigrante la constituye, sin duda, el país anfitrión, en el que reside y en el que ha construido su nueva infraestructura económica y familiar. El examen de las analogías a las que acuden los textos que componen el corpus para categorizar esta realidad permite descubrir variados dominios fuente ${ }^{9}$, SOLUCIÓn, ANFITRIón y sUeÑo, que confluyen en la caracterización del país receptor como entidad capaz de poner fin a las duras condiciones en que se desenvuelve la vida de estas personas en su lugar de origen, ligado, por contraposición, a la idea de peligro, de riesgo.

Sin embargo, según se constatará en la mayoría de las muestras extractadas, el hablante recurre a esta imaginería no para apoyarla, sino para negar su validez: efectivamente, los productores de nuestros textos tienen la percepción de que la actual política migratoria de EEUU supone una ruptura con la concepción tradicional de este país como pueblo que, fruto de sucesivas oleadas de inmigrantes, los acoge calurosamente ${ }^{10}$; recordemos en este sentido lo afirmado a propósito de la contextualización del corpus, que corresponde cronológicamente a un periodo en el que la ausencia de una reforma migratoria federal ha propiciado la aparición de leyes estatales heterogéneas con las que cada uno de los estados ha pretendido regular la situación de este colectivo; muchas de estas leyes han provo- cado que la comunidad latina de EEUU, además de otras minorías, se sienta amenazada por el impacto que estas medidas de control puedan tener sobre sus actuales condiciones de vida. Consecuentemente, los autores del corpus acuden a estas representaciones positivas del país anfitrión con el fin de refutarlas, de presentarlas como agotadas, como caducas, mediante expresiones lingüísticas que, de un modo u otro, explicitan la idea de que EEUU ya no es una solución, ya no es un anfitrión y, finalmente, ya no es un sueño.

La primera de las imágenes positivas del país anfitrión rechazada se dibuja a partir de un dominio fuente que, con la idea de no atomizar excesivamente el estudio, hemos formulado como solución, como entidad, institución o instrumento capaz de resolver dificultades. Las nociones de auxilio, protección, garantía y seguridad se activan mediante este dominio base solución, que se instancia en realidades diversas, según el nivel de importancia concedido al problema al que se busca remedio.

Algunas de estas instanciaciones, tales como salida de emergencia y válvula de escape, subrayan con gran impacto retórico la gravedad de la situación que pretende resolver el inmigrante cuando decide marcharse e insisten en la representación del país anfitrión como la vía para librarse de ella.

En la primera de las muestras, la única que no niega explícitamente la metáfora objeto de estudio, la salida de emergencia se proyecta en el dominio meta sobre el país anfitrión para categorizarlo como escapatoria, como lugar por

9 Los autores del corpus hacen uso, además, para representar figuradamente al país receptor, del esquema de imagen RECIPIENTE, que lo proyecta sobre un espacio limitado (el PAIS RECEPTOR DE INMIGRANTES ES UN RECIPIENTE), mediante una metáfora de amplia solera en el discurso hostil al fenómeno de la inmigración a la que, aquí, sin embargo, se le aplican los procesos cognitivos pertinentes que permiten reconocer el anclaje ideológico de sus nuevos usuarios. Efectivamente, estos asignan al inmigrante el rol de quien sufre la amenaza de ser expulsado del contenedor por las autoridades del país anfitrión, de ser deportado; frente al discurso xenófobo, que le asigna el rol de agente que amenaza a los ciudadanos del país en el que han decidido establecerse. Se trata de una metáfora estudiada en las páginas de otro trabajo.

10 Ellis y Wright (1998) recogen diversas metáforas que conceptualizan, desde perspectivas diversas, la asimilación de inmigrantes que tradicionalmente ha tenido lugar en la sociedad estadounidense: melting pot, quilt, kaleidoscope o salad bowl. 
donde podemos alejarnos de un daño que nos amenaza. Teniendo en cuenta la procedencia de los textos que integran el corpus, la situación de peligro que experimenta México requiere que algunos de sus ciudadanos recurran a la salida de emergencia, emigren al país vecino, que, de este modo, se retrata como lugar seguro, a salvo de aquello que amenaza:

Y ¿qué me dicen de Reforma, un pueblo del hermosísimo y líquido Tabasco donde vuelan las blancas mariposas? En la puerta del panteón municipal hay un letrero grande que a la letra dice: "Salida de emergencia". Eso hace que nazca en mí una triste idea: toda la frontera con Estados Unidos se ha convertido para los mexicanos -pobres y ricos por igual- en una gran salida de emergencia (FSD, 01-09-2011).

En el fragmento siguiente, sin embargo, en el que la solución se instancia en una válvula de escape, se niega explícitamente esta categorización del país de acogida como instrumento capaz de librar de dificultades mediante el enunciado México ya no tendrá esa válvula de escape que le evitó disturbios sociales durante décadas:

Este es un enorme cambio de actitud de los mexicanos. Y tiene profundas consecuencias. México ya no tendrá esa válvula de escape que le evitó disturbios sociales durante décadas (FSD, 13-102011)

Según se desprende de la topología de la metáfora, y al igual que en la muestra anterior, la máquina, proyectada en el dominio meta sobre México, experimenta un exceso de empuje, ejercido, en el dominio destino, por los ciudadanos mexicanos que carecen de los medios necesarios para subsistir en su país; en opinión del autor de la muestra, este exceso de presión se aliviaba en etapas anteriores propiciando su salida, la emigración, a través de la válvula de escape, proyectada sobre EEUU. El país receptor de inmigrantes se conceptuaba entonces como mecanismo que impedía la explosión que ocasiona un exceso de presión en la máquina.

Otras veces, la solución se identifica con realidades que, aunque implican un menor nivel de gravedad al evaluar las circunstancias de las que pretende alejarse el inmigrante, recogen esa categorización del país anfitrión como entidad calificada, si no para solucionar, sí para mejorar las condiciones de vida, para superar los obstáculos o dificultades que motivan la decisión de partir. No obstante, al igual que ocurría en el fragmento anterior, el hablante recurre a esta metáfora para poner de manifiesto un contraste entre el antes - como dice la muestra extractada - y la situación actual, en la que, según su criterio, esta imagen ya no es aplicable a EEUU:

Pero [México] se quedará con la energía, creatividad y visión de millones de jóvenes que antes veían al norte como su única opción para superarse (FSD, 13-10-2011)

Otra de las categorizaciones positivas del país de acogida, también refutada por nuestros autores, se produce acudiendo al marco origen ANFITRIÓN. La conceptualización de un estado como una entidad antropomórfica pone al descubierto la implicación emocional del usuario (Semino, 2008), que de este modo personifica al país receptor en un anfitrión que acoge calurosamente a sus invitados, los inmigrantes, quienes reciben el trato y la hospitalidad que merecen los convidados a su mesa. Sin embargo, tales proyecciones carecen de validez en la situación actual, en la que, según la afirmación del autor del fragmento siguiente, Estados Unidos ya no es percibido en el extranjero como el país que, tarde o temprano, acoge y da la bienvenida a los recién llegados:

Como si esto fuera poco, la actual campaña por la presidencia en Estados Unidos ha hecho que desaparezca hasta el 2013 cualquier posibilidad de una reforma migratoria que legalice a once millones de indocumentados. Estados Unidos ya no es percibido en el extranjero como el país que, tarde o temprano, acoge y da la bienvenida a los recién llegados (FSD, 13-10-2011).

Finalmente, se rebate la imagen positiva del país de destino construida mediante el dominio fuente sueño. Se trata de una metáfora tradicionalmente aplicada a EEUU como país de acogi- 
da desde que fue acuñada en 1931 por James T. Adams en su obra The Epic of America ${ }^{11}$. Con ella, el concepto de sueño, concebido como proyecto o deseo de difícil e improbable realización, se identifica en el espacio meta con EEUU, representado de este modo como el mejor de los destinos al que el inmigrante aspira, porque entiende que en él es posible encontrar lo que desea, lo que busca, lo que sueña. El país se identifica entonces con la promesa de una vida mejor, con ese lugar en el que todos, sin discriminación social, racial o religiosa, disponen de igualdad de oportunidades; en el que todos pueden lograr, con esfuerzo y determinación, la prosperidad, que cada individuo cifra en objetivos diversos, sean económicos, educativos o de otra índole ${ }^{12}$. Sin embargo, una vez más el usuario acude a esta imagen con el objeto de negar su vigencia en el presente, en el que, en su opinión, el sueño americano se ha desvanecido para transformarse, como veíamos en anteriores epígrafes, en una pesadilla:

En general, el análisis muestra que un número récord de todos los habitantes del "país más rico del mundo" están en la pobreza, un total de 49 millones 100 mil, especialmente los mayores de 65 años "gracias" al alto costo de los gastos médicos, deducibles de los seguros de salud y el precio de las medicinas. [...] El famoso "Sueño Americano", pues, ya nos está espantando hasta el sueño (LPSD, 09-12-2011).

Según hemos verificado, nuestros textos recurren a esta constelación de metáforas que configuran una imagen positiva del país anfitrión con el fin de rechazarlas, poniendo de manifiesto un contraste entre el pasado, en el que EEUU se identificaba con un rostro amable que acoge a los que arriban al país con el propósito de buscar mejores condiciones de vida, y el presente, en el que predomina una concepción negativa del país, que desarrolla políticas migratorias capaces de amenazar la infraestructura económica y familiar del inmigrante irregular. Por ello, los textos objeto de estudio manifiestan explícitamente su resistencia a establecer proyecciones entre el país de acogida y el marco conceptual solución, porque ya no lo reconocen por sus aptitudes para solventar problemas graves; de igual modo, niegan su correspondencia con el dominio fuente ANFITRIÓN, pues no conciben a ninguno capaz de tratar a quienes asiste en calidad de invitados como los autores de nuestros textos creen que es tratado el indocumentado; $y$, finalmente, niegan la identificación del país anfitrión con el marco sueño, porque entienden que ese sueño se ha trocado en pesadilla.

\subsection{Conceptualización metafórica de la aportación del indocumentado al país anfitrión}

Recogemos, finalmente, las expresiones metafóricas que conceptualizan la aportación del indocumentado al país anfitrión. Encierran, por tanto, la visión de lo que el inmigrante significa, en opinión de quienes suscriben estos textos, para el país en el que se ha establecido. En todas ellas subyace una misma metáfora conceptual, cuyo dominio fuente, de amplio espectro metafórico (Kövecses, 2002: 117-118), es la MÁQUINA'13, entendida como 'artificio para aprovechar, dirigir o regular la acción de una fuerza’'(DRAE, 2001).

A través de metáforas lingüísticas instanciadas unas veces mediante términos sustantivos,

11 En esta obra, Adams (1931) se refería a ese sueño en estos términos: "It is not a dream of motor cars and high wages merely, but a dream of social order in which each man and each woman shall be able to attain to the fullest stature of which they are innately capable, and be recognized by others for what they are, regardless of the fortuitous circumstances of birth or position".

12 Lakoff (2008: 21-42) expone su análisis de la narrativa que entraña la metáfora del sueño americano

13 El dominio fuente mAQUINA se utiliza también en nuestro corpus para conceptuar metafóricamente las leyes impuestas por el país receptor en su combate contra la inmigración irregular; con ello se indica que la fuerza de la máquina, la presión, se ejerce sobre una colectividad, la de los inmigrantes indocumentados, a los que, por medio de estas leyes, se aprieta o comprime. 
como impulso, fuerza y aliento, y otras, mediante el verbo construir o el sintagma mano de obra, se asocia figuradamente al inmigrante con una máquina, cuya fuerza, proyectada en el dominio meta sobre la capacidad de trabajo del inmigrante, se orienta a la producción de riqueza. Diríamos que esta analogía presenta un retrato del inmigrante en el que, de entre todas sus facultades, destaca su disposición para el trabajo como modo de contribuir al impulso de la economía del país anfitrión. Se subraya, como señalan Lakoff y Turner (1989: 197), la quintaesencia del dominio fuente y se utiliza para razonar sobre un atributo del dominio meta:

Los inmigrantes pagan impuestos, crean trabajos y toman los trabajos que ningún norteamericano quiere realizar. Son un extraordinario impulso a la economía de cualquier país (FSD, 13-10-2011).

La misma metáfora conceptual se advierte en el siguiente fragmento, donde la potencia de la máquina se proyecta en el dominio destino sobre los músculos del indocumentado, responsables de su movimiento; y el rugido, el resoplido del mecanismo, con el aliento de sus pulmones, con su impulso vital:

"Usted tiene mayores posibilidades de que lo parta un rayo que ser deportado, siendo un inmigrante ilegal en este estado y en este país", dijo el alguacil del condado de Rockingham, Sam Page, para defender el programa de deportaciones Comunidades Seguras, que ha sido cuestionado nacionalmente por no cumplir el propósito de expulsar criminales, sino humildes trabajadores que han dejado en este país la fuerza de sus músculos y el aliento de sus pulmones (EL, 15-122011)

En la muestra extractada a continuación, la máquina, en este caso constructora, orienta su energía, análoga a la del inmigrante indocumentado, al esfuerzo de edificar, de levantar figuradamente al país receptor, de impulsar su economía. Naturalmente, es una expresión en cuya base es posible reconocer una metáfora compuesta (Ruiz de Mendoza y Pérez, 2011), que surge de la combinación de diversas metáforas primarias, entre las que destaca una analogía convencional, EL PAís ES UN EDIFICIO (Chilton, 1996; Moreno Lara, 2005), del que los inmigrantes son sus constructores:

En este tiempo debemos celebrar también a los millones de trabajadores honestos que con su esfuerzo construyen país todos los días y a los estudiantes que se esfuerzan por superar barreras legales, culturales y lingüísticas para llegar a donde están sus sueños (LPSD, 23-09-2011).

Finalmente, en la misma línea de conceptualizaciones, se insiste en este retrato del inmigrante centrado en su capacidad de trabajo, destreza hacia la cual se dirige la atención del autor, por encima de otras que quedan en la sombra, y que aquí se subraya mediante la expresión cosa en que somos especialistas:

Porque eso sí, no se trata nomás de vivienda subsidiada y de cupones de comida, sino de trabajar, cosa en que somos especialistas. Haber deportado un millón de inmigrantes es haber deportado nuestra fuerza de trabajo (LPSD, 09-12-2011).

En definitiva, la cadena nominativa integrada por términos como impulso, fuerza, aliento, construir o la secuencia mano de obra infunde a este tipo de discurso coherencia intertextual e intratextual (Chilton y Schäffner, 2002: 29), sistematicidad local y discursiva (Cameron, 1999: 16), pues, a la vez que compone un retrato del indocumentado focalizado en su capacidad para trabajar, va urdiendo relaciones en el interior de un mismo texto y entre textos del mismo corpus, que, finalmente, distinguen y singularizan el lenguaje específico de estos artículos de opinión sobre la inmigración. Conviene señalar al respecto el contraste existente entre esta representación positiva del inmigrante, retratado como fuerza de trabajo que contribuye al levantamiento del país receptor, y la estampa que suele ofrecernos el discurso de carácter xenófobo, que construye su identidad resaltando esta misma facultad, pero esta vez con intención deslegitimadora: una fuerza de trabajo despojada de humanidad 
y destinada a ocupar las peores posiciones sociales y laborales; el colectivo hostil hacia el inmigrante está dispuesto a tolerarla temporalmente, pero se resiste a considerarla parte estable de la sociedad (Cachón, 1995). Como afirma Cachón (1997), el país receptor se opone a que las aves migratorias se transformen en seres humanos.

\section{Conclusiones}

Los estudiosos del discurso en torno a la inmigración se han ocupado preferentemente del retrato del inmigrante elaborado por sus detractores, quienes lo conceptúan como una realidad negativa $y$, por ello, como enemigo al que hay que combatir (Santa Ana, 1999, 2002, 2003; Flores, 2003; Cisneros, 2008; Semino, 2008; Musolff, 2011). Este discurso, con la intención de deslegitimar al inmigrante, lo categoriza metafóricamente acudiendo a dominios conceptuales diversos, tales como los desastres naturales, la guerra, la enfermedad o la herida, que comparten una evaluación negativa, en tanto que activan emociones y juicios descalificadores.

Naturalmente, este discurso dominante de carácter xenófobo ha generado una respuesta, efectuada por voces de ideología contraria, por los valedores sociales y políticos del inmigrante irregular, quienes, a través de estrategias legitimadoras, pretenden poner de manifiesto que los que pertenecen a este colectivo son miembros competentes y moralmente rectos del orden social. Se trata, por tanto, de un discurso de la solidaridad, que conceptualiza metafóricamente al inmigrante como un sujeto desvalido, que debe ser objeto de ayuda y comprensión.

Con el fin de analizar la conceptualización metafórica del inmigrante efectuada por estas voces que se solidarizan emocionalmente con él, hemos partido de un corpus constituido por artículos de opinión aparecidos en publicaciones en lengua española específicamente dirigidas a la población hispana residente en el condado estadounidense de San Diego y hemos analizado las metáforas conceptuales y lingüísticas a las que recurren estas voces para reproducir la vida del inmigrante irregular y ciertos aspectos relevantes del universo cognitivo en el que se desenvuelve.

De nuestro análisis se desprende que las asociaciones metafóricas empleadas con la función de legitimar la figura del inmigrante componen un retrato de tintes oscuros, escogidos en la vena del gris y del negro, con el que se pretende lograr que la audiencia lo respalde. Especialmente ilustrativos de esta paleta sombría son los tres marcos fuente seleccionados — PESADILLA, ACTIVIDAD ARRIESGADA O TABLERO DE AJEDREZ - para subrayar la angustia, el padecimiento, el peligro y la dificultad como notas dominantes de la vida de este grupo social.

En la misma línea de legitimación del inmigrante irregular se sitúa la imaginería escogida en nuestro corpus para conceptualizar realidades determinantes en su existencia, tales como el permiso de residencia o el país de acogida. Por lo que se refiere a la primera de estas realidades, el permiso de residencia, ese documento que tiene la capacidad de transformar radicalmente las condiciones de vida del inmigrante irregular liberándolo del estigma de la ilegalidad, se conceptualiza por medio del dominio fuente PAPEL, para expresar el menosprecio del indocumentado ante el rechazo o la exclusión que experimenta por la circunstancia de carecer de este papel, que lo degrada a una especie inferior; con esta proyección metafórica se introduce una réplica al discurso de los otros, quienes construyen la identidad del inmigrante irregular a partir de un objeto físico que tiene la capacidad de metamorfosearlo en persona radicalmente distinta, legal, aceptable. En cuanto a la segunda de las realidades citadas, el país de acogida, en el que el inmigrante ha sentado los cimientos de una nueva vida y en el que le ha sido posible superar las dificultades que lo llevaron a abandonar su tierra de origen, se acude a conceptualizaciones metafóricas positivas del país anfitrión con el fin de negarlas, de refutarlas; con el fin de poner de 
manifiesto un contraste entre la situación pasada, en la que el país receptor se identificaba con la imagen tradicional de EEUU como pueblo que acoge calurosamente al inmigrante -y que metafóricamente cristaliza acudiendo a los dominios fuente SOLUCIÓN, ANFITRIÓN Y SUEÑO-, y la situación presente, en la que esta imagen positiva queda desplazada por una concepción negativa, por una nación que desarrolla políticas migratorias capaces de amenazar la infraestructura económica y familiar del inmigrante irregular. De este modo, los textos objeto de estudio manifiestan explícitamente su resistencia a establecer proyecciones entre el país de acogida y el marco conceptual solución, porque ya no lo identifican por sus aptitudes para solventar problemas graves; de igual modo, niegan su correspondencia con el dominio fuente ANFITRIón, pues no conciben a ninguno capaz de tratar a quienes asiste en calidad de invitados como los autores de nuestros textos creen que es tratado el indocumentado; $y$, finalmente, niegan la correspondencia del país de acogida con el marco sueño, porque entienden que ese sueño se ha convertido en pesadilla.

A la ya citada estrategia de representación positiva del inmigrante responden también las expresiones metafóricas que recogen la visión de lo que este grupo social simboliza, en opinión de quienes suscriben estos textos, para el país receptor. En todas ellas reconocemos una misma metáfora conceptual, que asocia figuradamente al inmigrante con una máquina, cuya fuerza, identificada con su capacidad de trabajo, se orienta a la producción de riqueza. Se trata de una analogía que focaliza el retrato del inmigrante sobre una sola de las muchas facultades que lo definen, que es su disposición para el trabajo como modo de contribuir al levantamiento del país anfitrión, en contraposición con sus adversarios, que lo muestran como un lastre para la economía de la nación en la que residen.

En definitiva, las metáforas identificadas se emplean en estos textos con la intención de legitimar al inmigrante indocumentado, de conver- tirlo en miembro competente del orden social establecido; consecuentemente, tales metáforas contienen una narración cultural (Lakoff, 2008: 250), pues, además de una estructura dramática, disponen también de una estructura emocional, que repercute en la consideración moral de los personajes de la historia y que refleja la percepción de los que se sienten lesionados y oprimidos por el grupo social dominante. Son, por tanto, narrativas de opresión (Pinero-Pinero y otros, 2014), contrapunto de las narrativas de hegemonía identificadas en las metáforas empleadas por el discurso político norteamericano hostil hacia este colectivo en la prensa angelina (Santa Ana, 2002, 2003).

Tal y como advertíamos al comienzo, hemos desarrollado un estudio de naturaleza cualitativa que, mediante trabajos futuros, habrá de completarse con la exploración, a través de este mismo corpus, de la imaginería utilizada para categorizar otros aspectos relevantes del universo cognitivo del indocumentado, tales como las leyes y programas de control migratorio diseñados por el país anfitrión con la finalidad de combatir el fenómeno de la inmigración ilegal. De igual modo, conviene incrementar nuestra información con un estudio de carácter cuantitativo, que permita conocer el índice de frecuencia con que afloran estas metáforas conceptuales, tanto en este corpus como en otros que conforman ese hipergénero que, según Bañón (2002, 2008b), es el debate social, centrado en nuestro caso en la cuestión migratoria.

\section{Bibliografía citada}

Adams, James Truslow, 1931: The Epic of America, New York: Simone Publications.

Bañón Hernández, Antonio, 2002: Discurso e inmigración. Propuestas para el análisis de un debate social, Murcia: Universidad.

Bañón Hernández, Antonio, 2008a: "Análisis crítico del discurso de los medios de comunicación sobre las personas emigradas. Una mirada personal" en María Martínez Lirola (ed.): Inmigración, 
discurso y medios de comunicación, Alicante: Instituto Alicantino de Cultura Juan Gil-Albert, 23-44.

Bañón Hernández, Antonio, 2008b: "Mali y los inmigrantes malienses. Notas sobre la representación discursiva en el diario EL PAís" en Antonio Bañón y Javier Fornieles (eds.): Manual sobre comunicación e inmigración, San Sebastián: Gakoa, 171-200.

Cachón Rodriguez, Lorenzo, 1995: "Marco institucional de la discriminación y tipos de inmigrantes en el mercado de trabajo en España", Reis 69, 105-124.

Cachón Rodríguez, Lorenzo, 1997: "Segregación sectorial de los inmigrantes en el Mercado de trabajo en España”, Cuadernos de Relaciones Laborales 10, 49-73.

Cameron, Lynne, 1999: "Operationalising metaphor for applied linguistic research" en Lynne Cameron y Graham Low (eds.): Researching and Applying Metaphor, Cambridge: University Press, 3-28.

Casero Ripollés, Andreu, 2004: "Informando del otro: estrategias del discurso periodístico en la construcción de la imagen de los inmigrantes", Sphera Publica 4, 221-236.

Casero Ripollés, Andreu, 2007: "Discurso mediático, inmigración e ilegalidad: legitimar la exclusión a través de la noticia” en Ricard Zapata-Barrero y Teun A. van Dijk (eds.): Discursos sobre la inmigración en España: los medios de comunicación, los parlamentos y las administraciones, Barcelona: Fundación CIDOB, 69-92.

Chilton, Paul, 1996: Security Metaphors: Cold War Discourse from Containment to Common House, New York: Peter Lang.

ChILton, Paul, 2004: Analysing Political Discourse. Theory and Practice, London y New York: Routledge.

Chilton, Paul y Christina Schäffner, 2002: "Introduction: themes and principles in the analysis of political discourse" en Paul Chilton y Christina Schäffner (eds.): Politics as Talk and Text: Analytic
Approaches to Political Discourse, Amsterdam: John Benjamins, 1-41.

Cisneros, J. David, 2008: "Contaminated Communities: The Metaphor of 'Inmigrant as Pollutant' in Media Representations of immigration", Rhetoric \& Public Affairs 11, 4, 569-601.

Condor, Susan y Charles Antaki, 2000: "Cognición social y discurso" en Teun Adrianus van Dıjk (comp.): El discurso como estructura y proceso, Barcelona: Gedisa, 453-489.

Ellis, Mark y Richard WRIGHT, 1998: "The Balkanization Metaphor in the Analysis of U.S. Inmigration", Annals of the Association of American Geographers 88, 4, 686-698.

Flores, Lisa, 2003: "Constructing Rhetorical Borders: Peons, Illegal Aliens, and Competing Narratives of Inmigration", Critical Studies in Media Communication 20, 4, 362-387.

HAYNES, John, 1989: Introducing Stylistics, London: Hyman.

HeIlman, Robert Bechtold, 1968: Tragedy and MeIodrama: Versions of Experience, Seattle: University of Washington Press.

Johnson, Mark, 1987: The body in the mind: The bodily basis of meaning, imagination, and reason, Chicago: University Press.

Johnson, Mark, 1993: Moral imagination: Implication of cognitive science for ethics, Chicago: University Press.

KöveCSES, Zoltán, 2002: Metaphor: A practical introduction, Oxford: University Press.

KöveCSES, Zoltán, 2005: Metaphor in Culture. Universality and Variation, Cambridge: University Press.

Lakoff, George, 1987: Women, Fire, and Dangerous Things. What Categories Reveal about the Mind, Chicago y London: The University of Chicago Press.

LAKoff, George, 2006: Thinking points. Communi- 
cating our American values and vision, New York: Farrar, Straus and Giroux.

LAKofF, George, 2008: The Political Mind. Why You Can't Understand 21st-Century Politics with an 18th-Century Brain, New York: Penguin.

LaKofF, George y Mark Johnson, 1980: Metaphors We Live By, Chicago y London: University of Chicago Press.

LAKOFF, George y Mark Johnson, 1999: Philosophy in the flesh: The embodied mind and its challenge to Western thought, New York: Basic Books.

LakofF, George y Mark TuRner, 1989: More than Cool Reason. Field Guide to Poetic Metaphor, Chicago y London: University of Chicago Press.

Lovejor, Arthur, 1936: The Great Chain Of Being: A Study of the History of an Idea, Cambridge: Harvard University Press.

Martín Rojo, Luisa, Laura Pardo y Rachel WhitTAKer, 1998: "El análisis crítico del discurso: una mirada interdisciplinar" en Luisa MARtín Rojo y Rachel WhitTAKer (eds.): Poder decir o el poder de los discursos, Madrid: Arrecife, 9-33.

Martín Rojo, Luisa y Teun van Dıjk, 1998: "Había un problema y se ha solucionado. La legitimación de la expulsión de inmigrantes ilegales en el discurso parlamentario español" en Luisa Martín Rojo y Rachel WhitTAKer (eds): Poder decir o poder de los discursos, Madrid: Arrecife, 169-234.

Foucault, Michel, 2002: Historia de la sexualidad, vol. I: La voluntad de saber (traducción de Ulises Guiñazú), Buenos Aires, Siglo XXI.

Moreno Lara, María Ángeles, 2005: La metáfora conceptual y el lenguaje político periodístico: configuración, interacciones y niveles de descripción. Tesis doctoral, Servicio de Publicaciones de la Universidad de La Rioja.

Musolff, Andreas, 2011: "Migration, media and deliberate metaphors", Metaphorik.de 21, 7-19.
Osborn, Michael y John Bakke, 1998: "The melodramas of Memphis: Contending narratives during the sanitation strike of 1968", Southern Communication Journal 63, 3, 220-234

Pinero-Pinero, Gracia, Marina Díaz-Peralta y María J. García-Domínguez, 2014: "Metaphors of Irregular Immigration in the Spanish Language Press in the United States", Studia Neophilologica 86, 1, 51-65.

Real Academia Española, 2001: Diccionario de la lengua española, Madrid: Espasa-Calpe.

Ruiz de Mendoza Ibañez, Francisco José y Lorena PéREZ HeRnÁndeZ, 2011: "The contemporary theory of metaphors: myths, developments and challenges", Metaphor and Symbol 26, 161-185.

Santa Ana, Otto, 1999: "Like an animal I was treated': Anti-Immigrant Metaphor in US Public Discourse", Discourse \& Society 10, 191-224.

Santa Ana, Otto, 2002: Brown Tide Rising. Metaphors of Latinos in Contemporary American Public Discourse, Austin: University of Texas Press.

Santa Ana, Otto, 2003: "Three mandates for antiminority policy expressed in U.S. public discourse metaphors" en René Dirven, Roslyn M. Frank y Martin Pütz (eds.): Cognitive Models in Language and Thought. Ideology, Metaphors and Meaning, Berlin y New York: Mouton de Gruyter, 199-227.

Semino, Elena, 2008: Metaphor in Discourse, Cambridge: University Press.

SWeetser, Eve, 1990: From etimology to pragmatics: Metaphorical and cultural aspects of semantic structure, Cambridge: University Press.

Turner, Mark, 1991: Reading minds: The study of English in the age of cognitive science, Princeton, NJ: University Press.

Van Dıık, Teun Adrianus, 1996: "Análisis del discurso ideológico", Versión 6, 15-43.

Van Dıık, Teun Adrianus, 1999: Ideología. Una apro- 
ximación multidisciplinaria, Barcelona: Gedisa.

Van Dıık, Teun Adrianus, 2005: "Nuevo racismo y noticias. Un enfoque discursivo" en Mary NaSH, Rosa Tello y Núria Benach (eds.): Inmigración, género y espacios urbanos. Los retos de la diversidad, Barcelona: Edicions Bellaterra, 33-55.

Van Dıık, Teun Adrianus, 2006: "Discurso de las élites y racismo insitucional” en Manuel Lario BastiDA (ed.): Medios de comunicación e inmigración, Murcia: CAM. 